\title{
Launching a Permanent Out-of-Hour Interventional Radiology Service: Single-Center Experience from a German University Hospital
}

\section{Einführung eines interventionell-radiologischen Hintergrunddienstes: Erfahrungen eines deutschen Universitätsklinikums}

Authors

Affiliations
J. P. Goltz ${ }^{1}$, H. Janssen ${ }^{2}$, B. Petritsch ${ }^{1}$, R. Kickuth ${ }^{1}$

Institute of Radiology, University Hospital of Würzburg

Department of Neuroradiology, University of Munich, Campus Großhadern, München

\section{Key words}

- interventional procedures

- cost-effectiveness

- out-of-hour rota

- radiology workload

- emergency radiology received 21.3.2013 accepted 15.7.2013

\section{Bibliography}

DOI http://dx.doi.org/ 10.1055/s-0033-1350401

Published online: 30.8 .2013

Fortschr Röntgenstr 2014; 186: 136-141 @ Georg Thieme Verlag KG Stuttgart · New York . ISSN 1438-9029

\footnotetext{
Correspondence PD Dr. med. Jan Peter Goltz, EBIR

Institut für diagnostische und interventionelle Radiologie, Universitätsklinik Würzburg Oberdürrbacher Straße 6 97080 Würzburg

Germany

Tel.: ++ 49/0931/20134220

Fax: ++ $490931 / 20134212$

Goltz@roentgen.uni-

wuerzburg.de
}

\section{Zusammenfassung \\ v}

Ziel: Untersuchung der Realisierbarkeit, Einsatzhäufigkeit, Leistungen und Kosten eines formellen „Rund-um-die-Uhr“ interventionell-radiologischen (IR) Hintergrunddienstes.

Material und Methoden: Im November 2011 wurde ein formeller Hintergrunddienst für IR Leistungen eingeführt. Wir führten eine elektronische Abfrage unseres Dokumentationssystems nach IR Leistungen zwischen 1/2012 und 12/ 2012 ab, die außerhalb der regulären Arbeitszeiten erbracht worden waren. Elektive Fälle, die bis nach Ende der regulären Arbeitszeit andauerten, wurden von der Auswertung ebenso ausgeschlossen wie solche, bei denen der Hintergrunddienst zwar den Eingriff in der Dienstzeit begonnen, das Krankenhaus aber noch nicht verlassen hatte. Bestimmt wurden Art, Häufigkeit und Personalkosten $(€ / J a h r$ und Prozedur) des Hintergrunddienstes. Die Nachfrage zuweisender Fachbereiche wurde analysiert.

Ergebnisse: Während eines Zeitraums von 12 Monaten wurden die zuständigen Radiologen $(n=3)$ für 92 Interventionen ins Krankenhaus gerufen. Die Prozeduren umfassten Angiografien zur akuten Blutungskontrolle ( $\mathrm{n}=36,39,1 \%)$, Angiografien zur Therapie der akuten Extremitätenischämie $(n=25,27,2 \%)$, perkutane transhepatische Cholangiografien mit Drainage (PTCD) $(n=10,10,9 \%)$, Angiografien der Viszeralarterien bei non occlusive disease $(n=7,7,6 \%)$ und andere Interventionen $(n=14,15,3 \%)$. Die Personalkosten betrugen $€ 42312,21 \quad(€ 32982,60$ Bereitschaftspauschale, €9329,61 für geleistete Arbeitsstunden). Die Personalkosten pro Prozedur betrugen $€ 459,92$. Zuweiser waren Allgemeinund Viszeralchirurgie $(n=25)$, Gefäßchirurgie $(n=24)$, Innere Medizin $(n=21)$, Herz-/Thoraxchirurgie $(n=9)$, Unfallchirurgie $(n=5)$, Urologie $(n=5)$ und Anästhesie $(n=3)$.

\section{Abstract \\ $\nabla$}

Purpose: To evaluate the feasibility, frequency of use, types of intervention and labor costs of a formal round-the-clock interventional radiology oncall service.

Materials and Methods: In 11/2011 a formal and permanent out-of-hour interventional radiology rota in addition to the general radiology out-ofhour rota (OOHR) was established. We retrospectively screened the interventional radiology database for procedures completed outside regular working hours, reviewed all interventions and manually selected cases in which the on-call interventionist was called in from home. We determined the type, frequency of use and costs ( $€ /$ year and procedure) of this service between $1 / 2012$ and 12/2012. The referring physicians' (sub-) specialties were evaluated.

Results: During the 12-month period, the on-call interventionists $(n=3)$ performed 92 procedures $\mathrm{OOH}$. The procedures included angiography and hemorrhage control ( $n=36,39.1 \%$ ), angiography and intervention for acute limb ischemia $(n=25$, $27.2 \%$ ), percutaneous biliary drainage (PTCD) $(\mathrm{n}=10,10.9 \%)$, angiography for non-occlusive ischemia $(n=7,7.6 \%)$, and other $(n=14,15.3 \%)$. The total labor costs for the OOHR were $€ 42,312.21$ ( $€ 32,982.60$ lump sum for stand-by, $€ 9,329.61$ for hours spent on procedures). The labor costs per procedure totaled $€ 459.92$. The referring physicians' specialties were general/visceral $(n=25)$, vascular surgery $(n=24)$, internal medicine $(n=21)$, cardiac/thoracic vascular $(n=9)$, trauma surgery $(n=5)$, urology $(n=5)$, and anesthesiology $(n=3)$.

Conclusion: A formal interventional OOHR is practicable in a university hospital setting. Most procedures were requested by general, vascular, and thoracic surgery as well as internal medicine with a focus on hemorrhage control, treatment of 
Schlussfolgerungen: In einem universitären Umfeld ist ein IR „Rund-um-die-Uhr“ Hintergrunddienst realisierbar. Häufigste Zuweiser waren Allgemein-, Gefäß- und Herz-/Thoraxchirurgie sowie Innere Medizin. Die häufigsten Prozeduren umfassten die Therapie akuter Blutungen, Extremitätenischämien sowie PTCD. Die Personalkosten für einen solchen Dienst erscheinen moderat. Kernaussagen:

- Ein interventionell-radiologischer Hintergrunddienst ist in einem universitären Umfeld realisierbar.

- Die Personalkosten pro Prozedur erscheinen moderat.

- Die häufigsten Prozeduren umfassten die Therapie akuter Blutungen, Extremitätenischämien sowie PTCD.

\section{Introduction}

$\nabla$

Interventional radiology has increasingly been recognized as part of the treatment of emergency patients of all kinds including hemorrhage control, stent implantation for acute pathologies of the thoracic and abdominal aorta as well as other vascular emergencies, acute peripheral and visceral ischemia, biliary obstruction with sepsis and abscess drainage $[1,2]$. Especially the treatment of trauma patients increasingly relies on interventional procedures [3]. Major or level-1 trauma hospitals offer 24-hour emergency care and interventional procedures play an increasingly important role in the treatment of emergency patients. In this context the need for a well-trained interventionist on formal call has already been postulated [1]. Recent CIRSE guidelines for the endovascular treatment of traumatic hemorrhage [4] stress the importance of 24-hour availability of an interventionist capable of performing stent grafting and embolization techniques, whereas other recommendations even stipulate formal out-ofhour rota (OOHR) for all kinds of interventional radiology procedures [1]. Several studies regarding emergency interventional procedures have been published [5-7], but only minimal data on the availability of interventionists on call around the clock have been reported [8]. Although interventional radiology (IR) is of importance to the treatment of many life-threatening situations, at least in Great Britain a formal OOHR for IR is available in only approx $10 \%$ to $28 \%$ of hospitals which provide coverage for acute cases - a situation that might easily put emergency patients at risk $[1,8]$. To our knowledge, there is a lack of data regarding the provision of a formal out-of-hour interventional radiology service in major trauma centers throughout Germany, but a formal OOHR for IR seems to be uncommon, too. Therefore, in this study we analyzed the utilization, types of procedure, referring specialty and labor costs after launching a formal OOHR for interventional radiology procedures at a German university hospital.

\section{Materials and Methods}

The present study was performed at a university hospital located in a midsize town with 133,000 inhabitants. The medical center serves a surrounding area with approximately 1.5 million people. In 2012, 1400 beds were available throughout the hospital and 800 physicians were employed, including 30 radiologists (neuroradiology excluded). The annual number of interventional procedures carried out during regular working hours was 1621 (in 2010) and 1548 (in 2011). During regular working hours 111 (in acute limb ischemia, and PTCD. The overall labor costs for the OOHR appear moderate.

Key points:

- In a university setting an OOHR for IR is feasible.

- Labor costs per procedure appear moderate.

- Hemorrhage control and treatment of limb ischemia were the most frequent procedures.

Citation Format:

Goltz JP, Janssen H, Petritsch B etal. Launching a Permanent Out-of-Hour Interventional Radiology Service: Single-Center Experience from a German University Hospital. Fortschr Röntgenstr 2014; 186: 136-141
2010) and 129 (in 2011) emergency procedures were performed. Prior to launching the OOHR for IR, the general radiologist was responsible for interventional procedures, too. In the case of the radiologist needing assistance for a certain interventional procedure, an informal or "ad hoc" service was in use. In 2011 an interventionist was asked for assistance by the general radiologist on call in 55 cases.

In 11/2011 a formal and structured permanent out-of-hour interventional radiology rota (OOHR) was established in our radiology department in addition to the already existing general radiology out-of-hour rota. Three interventionists with 16 ("IR_16"), 5 ("IR_5") and 2 ("IR_2") years of experience in IR took part in this OOHR for IR procedures. Out-of-hour times at our institute of radiology are defined as those hours between $5 \mathrm{p} . \mathrm{m}$. and $8 \mathrm{a} . \mathrm{m}$. on work days (Monday to Friday) as well as from 4:30 p. m. on Fridays until 8 a. m. on Mondays (weekend) and 24 hours on public holidays. Retrospectively we performed a survey of the hospital database for those interventional radiology documents which were generated within the above-mentioned out-of-hour times between 1/12/2012 and 31/12/2012. The identified cases were entered into a Microsoft Excel ${ }^{\circledR}$ file which was used for data management and analysis. Subsequently all identified case documents were reviewed to exclude patients who had been treated as part of a routine day program which extended beyond regular working hours. These cases therefore did not represent an emergency procedure. The remaining patients were defined as emergency patients. Only cases in which the interventionist was called in from home were evaluated. $\bullet$ Fig. 1 shows the selection of cases as a flow chart.

We analyzed the age and gender of the patient as well as the duration and type of procedure. Duration was defined as the period of time between the first and the last image recorded during the procedure. Procedure types were classified as being a) a diagnostic angiography and endovascular procedure for hemorrhage control, b) diagnostic angiography and an endovascular procedure for acute limb ischemia, c) percutaneous transhepatic cholangiography with drainage (PTCD), d) diagnostic visceral angiography with optional catheter placement in the superior mesenteric artery for infusion of prostaglandin in non-occlusive mesenteric ischemia (NOMI) and e) various procedures (including explantation of infected port devices, stent graft implantation for acute aortic pathology, TIPS revision, intervention on hemodialysis access, fenestration of aortic dissection membrane and arterial foreign body extraction). The referring physicians' specialty or subspecialty was recorded. To calculate the labor costs of the OOHR, the underlying labor agreement (Marburger Bund, “TV-Ärzte", implemented on 6/30/2006) was used. In 2012 this 


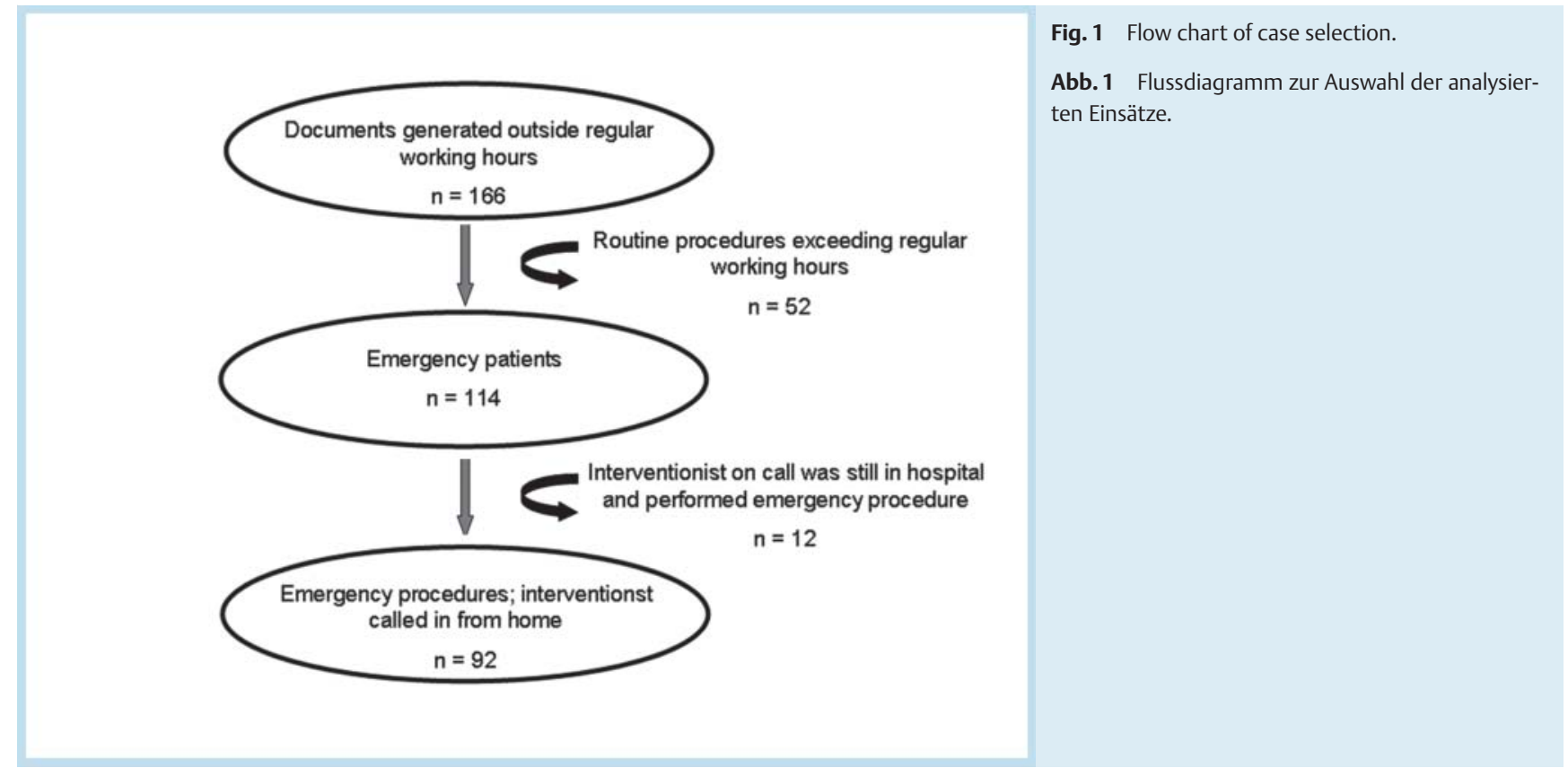

Table 1 Lump sum for OOHR for groups $\ddot{A} 2$ and $\mathrm{Ä} 3$ in 2012 per day.

Tab. 1 Pauschalen in den Gruppen $\mathrm{A} 2$ und Ä3 für eine Rufbereitschaft (pro Tag) im Jahr 2012.

\begin{tabular}{|c|c|c|c|c|}
\hline & $\begin{array}{l}\text { work Day } \\
(n=247)\end{array}$ & $\begin{array}{l}\text { saturday } \\
(n=52)\end{array}$ & $\begin{array}{l}\text { sunday } \\
(n=53)\end{array}$ & $\begin{array}{l}\text { public } \\
\text { Holiday } \\
(n=14)\end{array}$ \\
\hline Ä2 & $€ 58.28$ & $€ 116.56$ & $€ 116.56$ & $€ 116.56$ \\
\hline Ä3 & $€ 73.02$ & $€ 146.04$ & $€ 146.04$ & $€ 146.04$ \\
\hline
\end{tabular}

Table 2 Per hour wages for actual call for groups Ä2 and Ä3 in 2012.

Tab. 2 Entgelt für tatsächlich geleistete Einsätze in den Gruppen Ä2 und Ä3 im Jahr 2012 (pro angefangene Stunde).

\begin{tabular}{|lllll|} 
& work day & saturday & sunday & $\begin{array}{l}\text { public } \\
\text { holiday }\end{array}$ \\
\hline$\ddot{\mathrm{A}} 2$ & $€ 30.42$ & $€ 30.00$ & $€ 36.43$ & $€ 68.48$ \\
\hline$\ddot{\mathrm{A}} 3$ & $€ 37.79$ & $€ 37.50$ & $€ 45.64$ & $€ 85.80$ \\
\hline
\end{tabular}

contract included a lump sum per day for OOHR ( $\bullet$ Table 1 ). In addition every actual call during the OOHR was compensated ( Table 2) and paid per commenced full hour (ranging from call of the interventionist at home until return home). The labor agreement differentiates between two groups ("Ä2" and "Ä3") of consultants. During the study period one staff in group Ä2 and two sets of staff in group Ä3 took part in the OOHR for interventional procedures. The overall case-related hours spent on each emergency case were multiplied by the applicable wage rate per hour and added to the lump sum for the 12-month period in order to calculate the overall labor costs for the out-of-hour rota for interventional emergency procedures in 2012. The distribution of calls during the out-of-hour period was analyzed and highlighted as a diagram.

\section{Results}

$\nabla$

The electronic search for interventional procedures within our hospital database identified 166 procedures terminated after regular working hours in 2012. After reviewing each case, a total of 92 patients ( 59 men, 33 women, mean age $65+/-17 y$ ) were finally identified as having had an emergency procedure for which the on-call interventionist was called in. The number of days spent on call was 121 (IR_2), 120 (IR_5) and 125 (IR_16). The mean procedure time was 58 minutes (range, 7-323 min.) for the three interventionists. The individual mean procedure times were $45 \mathrm{~min}$. (IR_16), $69 \mathrm{~min}$. (IR_5) and $64 \mathrm{~min}$ (IR_2).• Table 3 provides an overview of the type and frequency of the procedures performed out-of-hour by the on-call interventionist.

All but one procedure was completed by the on-call interventionist including the interventionist with two years of continuous IR experience. In this patient with acute hemorrhage following pancreatic surgery, the on-call interventionist (IR_2) asked a more experienced colleague (IR_16) for assistance as covered stent implantation was to be performed instead of coil embolization and complex anatomy was present.

The referring physicians' (sub-) specialties were general/visceral surgery $(n=25)$, vascular surgery $(n=24)$, internal medicine $(n=21)$, cardiac and thoracic vascular surgery $(n=9)$, trauma surgery $(n=5)$, urology $(n=5)$ and anesthesiology $(n=3)$.

During the week 50/92 (54.4\%) cases were performed out-ofhour, 38/92 (41.3\%) took place at the weekend and 4/92 (4.4\%) on a public holiday. The distribution of $\mathrm{OOH}$ procedures performed after regular working hours is shown in $\mathbf{~ F i g . ~} \mathbf{2 a}$, b.

The total costs for stand-by duty only (lump sum) for 12 months were $€ 32,982.60$, while the costs for actual in-call hours spent on procedures totaled $€ 9,329.61$. The overall costs for the OOHR during the evaluated 12 -month period were $€ 42,312.21$. The labor costs per procedure performed by the on-call interventionist were $€ 459.92$. 
a
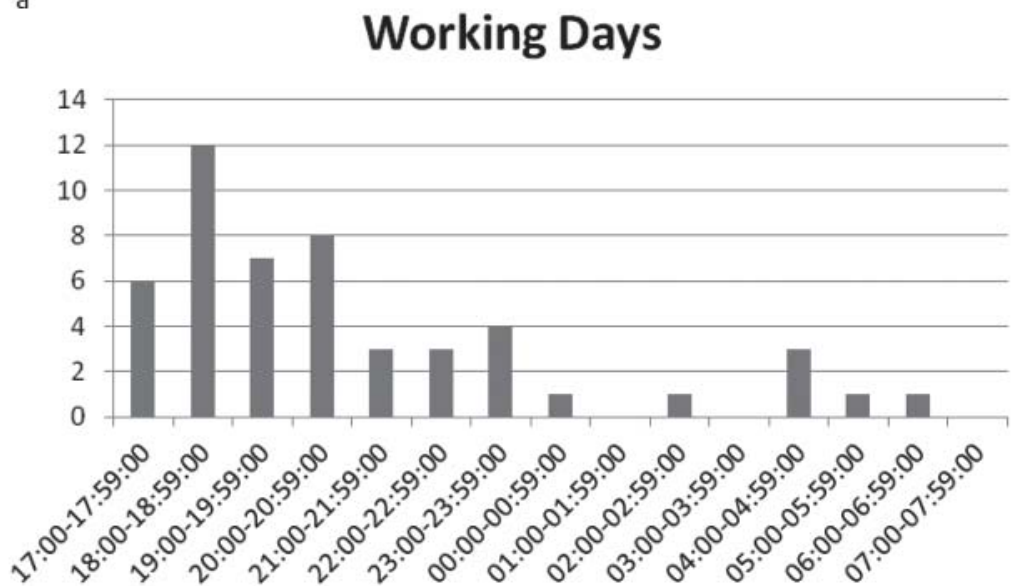

b

\section{Weekends and Public Holidays}

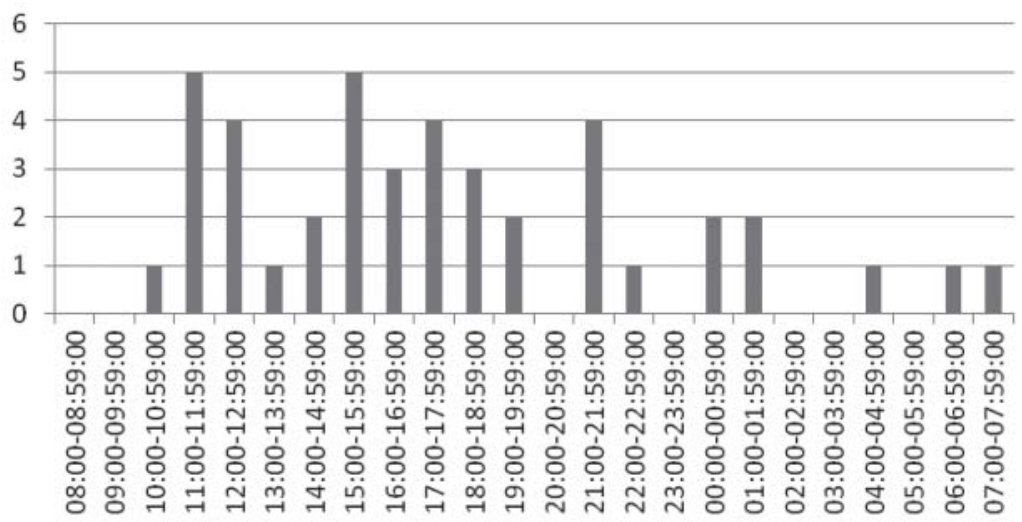

Fig. 2 a Distribution of in-call time during working days. b Distribution of in-call time during weekends and public holidays.

Abb. 2 a Häufigkeitsverteilung der Einsätze in Rufbereitschaft nach Tageszeit an Wochentagen. b Häufigkeitsverteilung der Einsätze in Rufbereitschaft nach Tageszeit an Wochenenden und Feiertagen.
Table 3 Type and frequency of procedures performed out-of-hour.

Tab. 3 Art und Häufigkeit der im Rufbereitschaftsdienst durchgeführten Prozeduren.

\begin{tabular}{|c|c|c|}
\hline type of procedure & number & percentage \\
\hline $\begin{array}{l}\text { diagnostic angiography and hemorrhage } \\
\text { control }\end{array}$ & 36 & $39.1 \%$ \\
\hline $\begin{array}{l}\text { diagnostic angiography and intervention for } \\
\text { acute limb ischemia }\end{array}$ & 25 & $27.2 \%$ \\
\hline PTCD & 10 & $10.9 \%$ \\
\hline $\begin{array}{l}\text { diagnostic visceral angiography for NOMI + } \\
\text { optional infusion of prostaglandin }\end{array}$ & 7 & $7.6 \%$ \\
\hline port explantation & 4 & $4.4 . \%$ \\
\hline stent graft, thoracic aorta & 3 & $3.3 \%$ \\
\hline TIPS revision & 3 & $3.3 . \%$ \\
\hline fenestration of aortic dissection membrane & 2 & $2.2 \%$ \\
\hline hemodialysis fistula intervention & 1 & $1.1 \%$ \\
\hline arterial foreign body extraction & 1 & $1.1 \%$ \\
\hline
\end{tabular}

\section{Discussion}

Today IR plays a relevant role in the minimally invasive treatment of several acute pathologies, e.g. aortic rupture, acute limb ischemia, biliary and renal obstruction, failing hemodialysis access and hemorrhage [1, 2, 9-12]. Studies have shown that the utilization of IR is able to lower the need for laparotomy and the rate of complications in non-operatively managed trauma patients [13]. Certain guidelines have stated that if endoscopic treatment has failed, IR is the second-line treatment for gastro-intestinal bleeding $[3,14]$. In this context recent guidelines and standard-ofpractice documents emphasize the importance of having an experienced interventionist available around the clock who is able to perform procedures in all of the above-mentioned acute scenarios $[1,4]$. To withhold IR treatment from certain patients may lead to a worse outcome, more invasive traditional surgical procedures and put patients at a relevant risk [1,3]. As reported by Illing et al. [8], the "real world scenario" will differ significantly from the above-mentioned recommendation: the authors found a formal OOHR for IR to be installed in $28 \%$ of evaluated hospitals in the London area with $58 \%$ offering an "ad hoc" service for cer- 
tain but not all interventional procedures. IR coverage for the treatment of bleeding complications from pelvic fractures has been described by other specialities as patchy and often unavailable [15]. To our knowledge, a formal and 24/7 OOHR for IR may exist at certain university hospitals in Germany, but seems to be rare amongst the majority of all German hospitals even with major trauma centers only offering an "ad hoc" service for IR procedures as reported earlier by a Scottish working group [3]. Data regarding the availability of a formal IR service amongst major hospitals would be of interest. One possibility to gain more data would be to extend the already existing voluntary quality management program [16] of the Germany Society of Interventional Radiology (DeGIR) specifically into the field of interventional emergency procedures. In this context we found it of interest to analyze the practicability, frequency of use, types of interventions and labor costs of a formal round-the-clock interventional radiology on-call service.

One reason for launching a 24/7 OOHR service for IR procedures was the feeling of the general radiologists on call that the number and complexity of cases is continually increasing. Furthermore, not all colleagues who participated in the general radiology $\mathrm{OOH}$ service felt comfortable performing more complex interventions.

Our data have shown the practicability of a formal 24/7 OOHR for IR procedures during a 12-month period in a University hospital setting. Although the formal rota consisted of only three radiologists, it was possible to launch a formal and permanent IR rota. On the other hand, one can easily calculate that this results in a heavy workload per interventionist and the need for more staff that is able to take part in such an OOHR for 24/7 IR care to reduce the workload per participant. Zeally et al. [3] stated that many hospitals are limited in offering such a service owing to a lack of properly trained IR nursing staff. This topic was not evaluated in the present study, but in our hospital it was easily possible to ensure that an adequately trained IR technician was available on a 24/7 basis.

In our opinion one major problem in launching an OOHR for IR is represented by the fact that not enough radiologists may be able to gain adequate experience in the treatment of all above stated emergencies, especially if the overall workload of the radiology department is high anyway. However, this experience strongly depends on the spectrum of interventional procedures performed on a regular basis within each IR department. Consequently, in our study we observed the lowest mean procedure time ( $45 \mathrm{~min}$.) for the most experienced interventionist when compared to the two less experienced interventionists (69 and $64 \mathrm{~min}$.). However, these results have to be interpreted with caution since the complexity of cases might not have been the same for the participating interventionists. In this context, recommendations have stated that radiologists should not perform procedures they are not familiar with [1]. At least for vascular interventional procedures, DeGIR has published a guideline on the minimal requirements of interventional radiologists' training and experience, although this does not specifically include emergency procedures $[17,18]$. More IR staff, which could be trained during regular working hours, might represent a possibility to overcome this problem. Somewhat contrary to this, Christie et al. [2] concluded in another paper that if a formal OOHR for IR is to be launched, participating radiologists should be trained for the most frequently requested procedures (embolization and nephrostomy in their study sample) and the inability to perform complex interventions should not impede initiation of 24/7 IR care. In our setting embolization for hemorrhage control, diagnostic angiography and techniques for revascularization in acute limb ischemia comprised the majority of the requested procedures (68/92, 73.9\%), suggesting that expertise in these techniques would be of benefit to participate in such a service.

Although it was not the subject of this study, the authors believe that a formal OOHR for 24/7 IR care is of importance to referring colleagues and may alter therapeutic regimes and clinical pathways of certain emergency patients. We believe that area-wide 24/7 coverage for IR is important to gain its overall acceptance and should be a matter of course as it would be for any other therapeutically working clinical subspecialty, not only but certainly in major hospitals.

We found a high utilization frequency (92 procedures during 12 months) of the OOHR, especially when comparing this number with that of the "ad hoc" service during the year prior to launching the OOHR for IR procedures (approximately double the number). In this context we find it important to highlight that we used strict criteria to define on-call procedures as described before [19]: only if the interventionist on call had been called in for a procedure did we define the procedure to have been undertaken "out-of-hour", as outlined in 0 Fig. 1. This method of evaluation ignores cases that were started and performed urgently within regular working hours with the result that a more elective case that was started after the urgent case might have extended beyond regular working hours but nevertheless have been performed by the "day shift". Furthermore, we did not take into account cases $(n=12)$ for which the interventionist on call was still in hospital and performed the procedure. Therefore, the presented data might underestimate the potential utilization of an $\mathrm{OOHR}$ for IR procedures.

Regarding the costs of an OOHR for IR, we found the sum of $€ 459.92$ per procedure to be moderate. Although this was not the subject of our study, one may take into account that withholding certain IR procedures may not only have serious implications for the patient but also result in higher costs owing to more invasive (surgical) procedures or longer procedure times if performed by a less experienced general radiologist [1, 3]. IR has been shown to be able to lower complications, e.g. in the nonoperative management of complex cases [13]. Again not proven by our data, it seems likely that fewer complications result in lower costs. However, it will be difficult to gain adequate data to prove this, as it appears unethical to perform a randomized study in such an emergency setting.

The presented study has limitations: the evaluation was retrospective and performed as a single-center analysis. Additional data from other major hospitals might draw a different picture, since regional, structural and intra-hospital pathways may differ significantly. Furthermore, the presented data include only the first-year analysis after launching the OOHR for IR. It can be speculated that with an ongoing service the number of patients treated may increase owing to a growing consciousness and acceptance for IR among referring physicians.

In conclusion, the presented data have shown that launching a formal and permanent out-of-hour rota for interventional radiology procedures in a university hospital setting is practicable at moderate labor costs per procedure. Procedures for hemorrhage control, revascularization in acute limb ischemia and treatment of biliary obstruction made up the majority of requested procedures. The spectrum of $\mathrm{OOH}$ IR procedures is reflected by the anchorage within interdisciplinary algorithms. 


\section{Clinical relevance of the study}

$\nabla$

- Interventional radiology (IR) has increasingly been recognized as a relevant part of the treatment of emergency patients of all kinds, including hemorrhage control, treatment of acute limb ischemia, acute aortic pathologies and others.

- Since emergency procedures need to be available around the clock, only a formal IR out-of-hour rota will secure comprehensive coverage for all requested and necessary procedures.

- Withholding certain IR procedures from emergency patients might put them at risk and may have a worse outcome or require more invasive traditional surgical procedures.

\section{References}

1 The Royal College of Radiologists (RCR). Standards for providing a 24hour interventional radiology service; 2008, http://wwwrcracuk/ docs/radiology/pdf/Stand_24hr_IR_provision.pdf

2 Christie A, Robertson I, Moss J. Interventional radiology emergency service provision for a large UK urban population: Initial 3.5 years of experience. Clin Radiol 2013; 68 (8)

3 Zealley IA, Gordon TJ, Robertson I et al. Provision of out-of-hours interventional radiology services in Scotland. Clin Radiol 2012; 67: 855 - 861

4 Chakraverty S, Flood $K$, Kessel $D$ et al. CIRSE guidelines: quality improvement guidelines for endovascular treatment of traumatic hemorrhage. Cardiovasc Intervent RadioL 2012; 35: 472 - 482

5 Mohan PP, Rozenfeld M, Kane RA et al. Nationwide trends in abdominal aortic aneurysm repair and use of endovascular repair in the emergency setting. J Vasc Interv Radiol 2012; 23: 338 - 344

6 Pellerin O, Bats AS, Di Primio M et al. Postpartum hemorrhage treated with gelfoam slurry embolization using the superselective technique: immediate results and 1-month MRI follow-up. Cardiovasc Intervent Radiol. 2013; 36: 98 - 104
7 Goltz JP, Basturk P, Hoppe H et al. Emergency and elective implantation of covered stent systems in iatrogenic arterial injuries. Fortschr. Röntgenstr 2011; 183: 618-630

8 Illing RO, Clark CL, Allum C. Provision of out-of-hours interventional radiology services in the London strategic health authority. Clin Radiol. 2010; 65: 297-301

9 Zealley IA, Chakraverty S. The role of interventional radiology in trauma. BMJ 340: c497

10 Schaefer PJ, Jahnke T, Muller-Hulsbeck S et al. Outcome of Immediate Interventions in Acute Dysfunctional Hemodialysis Fistulas. Fortschr. Röntgenstr. 2013; 185: $228-234$

11 Lesperance K, Andersen C, Singh $N$ et al. Expanding use of emergency endovascular repair for ruptured abdominal aortic aneurysms: disparities in outcomes from a nationwide perspective. J Vasc Surg 2008; 47: 1165 - 1170 discussion 1161-1170

12 Puls R, Rosenberg C, Kuhn JP et al. Thoracic aortic interventions. Fortschr. Röntgenstr. 2012; 184: 15-23

13 Gaarder C, Naess PA, Eken T et al. Liver injuries-improved results with a formal protocol including angiography. Injury 2007; 38: 1075-1083

14 Palmer K, Nairn M. Management of acute gastrointestinal blood loss: summary of SIGN guidelines. BMJ 2008; 337: a1832

15 Metcalfe AJ, Davies K, Ramesh B et al. Haemorrhage control in pelvic fractures-a survey of surgical capabilities. Injury. 2011; 42: 10081011

16 Heuser L, Arnold CN, Morhard D et al. Quality report 2011 of the Germyn Society of Interventional Radiology (DeGIR) - report about treatment quality of minimal invasive procedures. Fortschr. Röntgenstr 2012; 184: $570-576$

17 Bucker A, Gross-Fengels W, Haage P et al. Qualification guideline of the German Roentgen Society and the German Society of Interventional Radiology and Minimal Invasive Therapy for performing interventional radiologic minimal invasive procedures on arteries and veins Fortschr. Röntgenstr 2012; 184: 565-569

18 Helmberger T. Interventional radiology: state of the art. Fortschr Röntgenstr 2012; 183: 796-798

19 Surash S, Robertson I, Calvey TA et al. An audit of out of hours interventional vascular radiology. Eur J Vasc Endovasc Surg 2003; 25: 573 - 577 